\title{
Terpene Compound
}

National Cancer Institute

\section{Source}

National Cancer Institute. Terpene Compound. NCI Thesaurus. Code C860.

The class of compound known as terpenes comprise of essential oils, flavours and fragrances. The extraction and synthesis of compounds such as these is the basis for the perfumery industry. They find a variety of uses in the food and pharmaceutical industry as flavour and odour improvers 